\title{
Factors Affecting Quality of Sleep in Hospitalized Patients : A- Questionnaire Cross Sectional Study
}

\author{
Kavyashree. $\mathrm{M}^{1}$, Brundha M.P2* and Leslie Rani ${ }^{3}$ \\ ${ }^{1}$ Department of General Pathology, Saveetha Dental College, Saveetha Institute \\ of Medical and Technical Sciences, Saveetha university, Chennai, Tamil nadu. \\ ${ }^{2}$ Associate Professor, Department of General Pathology, Saveetha Dental College, \\ Saveetha Institute of Medical and Technical Sciences, Saveetha university, 162, \\ Poonamallee High Road, Chennai-600077 Tamil Nadu, India. \\ ${ }^{3}$ Lecturer Department of General Pathology Saveetha Dental College, Saveetha Institute of Medical \\ and Technical Sciences 162, Poonamallee High Road Chennai-600077 Tamil Nadu, India.
}

\section{ABSTRACT}

Promoting a peaceful environmental place to sleep in the hospital is very complicated and challenging. Even though a patient may try to sleep in the hospital, it may not be refreshing or restorative because of the following factors like environmental, physiological and psychological. These factors can work concomitantly, making sleep virtually impossible for some patients. Nurses can help their patients by understanding what influences their disturbing sleep patterns. The aim of the study is to know the factors that affect the quality of sleep in hospitalised patients. A cross- sectional questionnaire study was conducted among 100 hospitalised patients of Saveetha Dental College. Their answers were compared with the Farsi Pittsburgh sleep index and graphs have been plotted. Inclusion criteria: Selection criteria includes age greater than or equal to 18 years and completely conscious patients, patients hospitalized for more than two weeks. Exclusion criteria: Recently hospitalized patients , patients who received hypnotics or sedative drug over the last $24 \mathrm{~h}$, history of any major organ failure that may be associated with impaired conscious level and patients with sleep apnea were excluded.Statistical analysis was done using the SPSS software version 22. Descriptive statistics were expressed by means of frequency and percentage. Chisquare tests were used to find the association between the variables.We found that environmental factors affect the quality of sleep by $40 \%$ of the study population, Physiological factors affect $30 \%$ of the study population and Psychological factors affect the remaining 30\% of the study group.The environmental and physiological factors have more influence on the disturbed sleep pattern on hospitalized patients. The proper preventive measures must be taken to improve the sleep quality.

KEY WORDS: PHYSIOLOGICAL, ENVIRONMENTAL, SLEEP, DISTURBANCE, PSYCHOLOGICAL.

\section{ARTICLE INFORMATION}

*Corresponding Author: brundha.sdc@saveetha.com

Received 12th June 2020 Accepted after revision 10th August 2020

Print ISSN: 0974-6455 Online ISSN: 2321-4007 CODEN: BBRCBA

Thomson Reuters ISI Web of Science Clarivate Analytics USA and Crossref Indexed Journal

$$
\begin{aligned}
& \text { Clarivate } \\
& \text { Analytics }
\end{aligned}
$$




\section{INTRODUCTION}

Sleep is an unconscious state in which the person can be woken by any stimuli(Júnior et al., 2014). Electroencephalogram (EEG) monitoring shows that there are five distinct stages of sleep, which can be subdivided into two groups - non-rapid eye movement (NREM) sleep and rapid eye movement (REM) sleep. The first group, NREM sleep, has four stages, and the second, REM sleep, has only one stage. In the former, eye movement is virtually non- existent whereas in the latter the eyes move rapidly under closed eyelids NREM sleep as 'an idle brain in a very relaxed body' and REM sleep is 'a brain that appears wide awake in a virtually paralysed body'. During NREM sleep, breathing and heart rate decrease, muscles relax, and the brain's metabolic rate is reduced by $25-30 \%$. Whereas in REM sleep heart rate increases, the brain's metabolic rate is similar to being awake, and muscles, with the exception of smooth muscles, diaphragm, heart and eye muscles, are in a state of near paralysis (Whitehead, 1976).

Sleep is a cyclical process that is composed of five alternating and mutually different stages or phases. Due to the presence or lack of rapid eyes movement and changes in other variables such as muscle tension and cardiorespiratory pattern there will be change in the pattern of brain waves (Knutson et al., 2007). Sleep is important for humans and it's alteration in quality and quantity can affect the physical well being and health of the individual (Tranmer et al., 2003). Sleeplessness leads to copious negative cognitive, metabolic, autonomic and hormonal changes(Shenoy and Brundha, 2016)that leads to profound physical effects including fatigability, pain intolerance, miscerption, disorientation, decreases immune function and reduced secretion of growth hormone lead to regulate the body body growth and stimulate tissue restoration by anabolic activity(Rosenberg, 1990).

Mostly the hospitalised patient suffers from the sleeping disorder after surgery or during surgery. Hospitalized patients often have difficulty in initiating and maintaining sleep or complain of early awakening and non restorative sleep (Gangwisch et al., 2006). The cause of sleep disruption is multifactorial and includes the patient's underlying illness, medical treatments and hospital environment. Often unrecognized and untreated during hospitalization sleep disruption may lead to sleep deprivation or chronic lack of restorative sleep ('NIH State-of-the-Science Conference Statement on Manifestations and Management of Chronic Insomnia in Adults', 2009). Health individual, sleep deprivation can result in numerous physical and psychological consequences. Sleep deprivation is associated with hypertension impaired postural control, decreased ventilatory drive, increased sympathetic cardiovascular 02 activation and blunted hypothalamic pituitary adrenal axis and impaired host defenses and possibly diabetes mellitus and obesity(Besedovsky, Lange and Born, (2012).

Lack of restorative sleep increases the risk of developing anxiety and mood disorder and delirium, especially in acutely ill older patients(Ogawa et al., 2003). The presence of acute sleep may cause compound illness and impair recovery (Fabbri et al., 2006). Hospitalized patients usually have difficulties in meeting the need for sleep and this may be due to the changes in their sleeping and resting phase behaviors and habits. However, these patients have less sleep due to many factors that cause sleep disorders such as environment and the surrounding conditions. Such lack of sleep and rest can increase the cardiovascular risk consequences. It increases the sympathetic system activity resulting in a rise in blood pressure and heart rate (Adam and Oswald, 1977). There were numerous studies on analyzing the quality of sleep in college students as they were under stress and were home sick. This study was conducted to assess, analyse and evaluate the quality of sleep of the patients who were hospitalized for more than two weeks irrespective of the disease conditions and treatment therapy.

\section{MATERIAL AND METHODS}

A cross- sectional survey was conducted among 100 patients of Saveetha Dental College and Hospital.Nearly 20 questions had been prepared and it was asked to the patient and answers were recorded. Accordingly, the graph has been plotted with the help of the Farsi Pittsburgh sleep index.

Sampling: In the present study,the sampling method used is a random sampling method.

Data Collection and Tabulation: The number of questions distributed was 10.The close ended yes or no type of question were asked.Their responses were entered into the excel sheets and then tabulation of the data finally and the question comparison was done. The representation of the data is through the bar graph.

Statistical Analysis: The statistical software used IBM SPSS V22.The statistical test used is Chi square test ( $p$ value).Type of analysis used were descriptive analysis,demographic data.

Inclusion Criteria: Selection criteria include age greater than or equal to 18 years and conscious patients. Patients hospitalized for more than two weeks.

Exclusion Criteria: Patients who received any hypnotics or sedative drug over the last 24 hours, history of any major organ failure that may be associated with impaired 
conscious level and patients with sleep apnea were excluded. All patients were subjected to full history taking including symptoms related to sleep-disordered breathing, routine laboratory workup, and arterial blood gas analysis. Also, presence of comorbidity (hypertension or diabetes) was reported.

\section{RESULTS AND DISCUSSION}

Sleep is universally recognized as essential for physical and psychological healing and the restoration of overall well being throughout the ages. This study helps to describe that sleeping pattern of a patient in the hospital. The following questions were prepared accordingly into four factors. They are physical, physiological, environmental and psychological factors. Majority participants were female between the age of 40-50 years ,married, with normal education qualification.

Nearly 50 hospitalized patients from ICU and General In Patient ward were selected for the study. The obtained result shows that most of the patients suffer from sleep disorder in hospitalized condition. Various questions were asked and were compared the quality of sleep at home to the hospitalized condition. When asked to describe factors affecting night time sleep quality, nearly $60 \%$ female and $40 \%$ of Male patients responded (Figure 1).As for gender, for example, a study undertaken with 150 patients in a hospital concluded that men had better sleep quality than women because women are always more concerned about not performing their home duties and caring for their families during their stay in the hospital(Dogan, Ertekin and Dogan, 2005).

Figure 1: Pie chart shows the result of people participated in the study, $60 \%$ female respondents(red) and 40\% male respondents (blue)

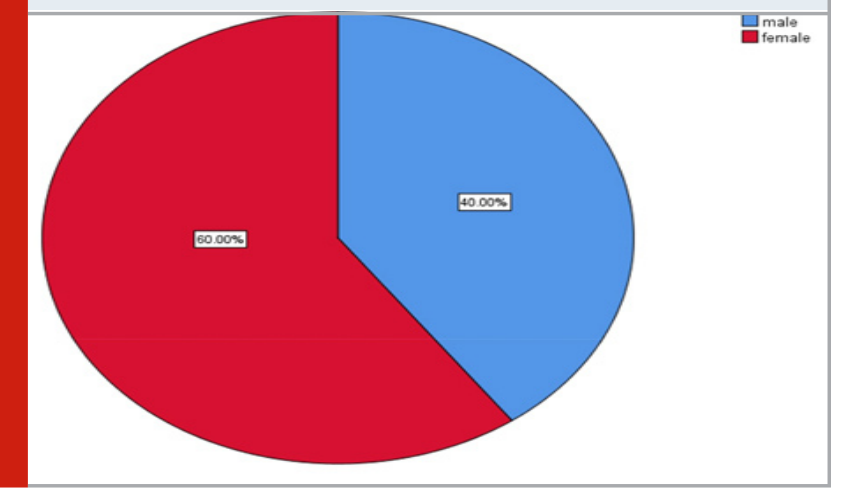

Figure 2 shows, Environmental factor affects (40\%) physiological factors affects (30\%)and psychological factor affects (30\%)of the patients. Figure 3 represents the association between gender and factor affecting the quality of sleep in hospitalised patients and it was shown females have been affected more commonly than males by environmental, physiological and psychological factors. Chi square test was used to find the association between the variables, Pearson chi square value is 1.389 , $p$ value is $0.499(>0.05)$ and was found to be statistically not significant.

Figure 2: Pie chart shows the results on factors affecting the quality of sleep in hospitalized patient ,40\%by environmental factor(blue) ,30\% physiological factor (red) and $30 \%$ psychological factor(Green)

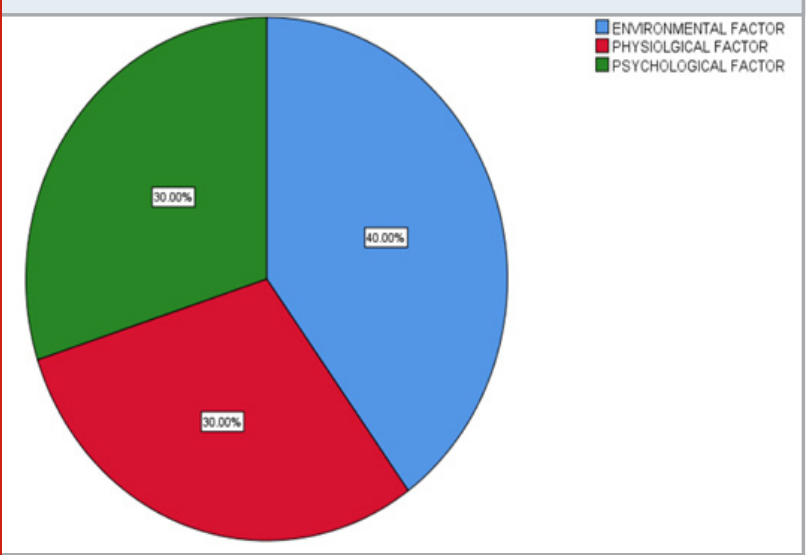

Physical activity positively affects sleep quality. Particularly for the elderly, physical exercise has been shown to be beneficial for sleep problems related to disorders of the circadian rhythm, such that regular physical activity seems to increase the depth and duration of sleep(Sin, Ho and Chung, 2009). While analyzing the reports the sleep characteristic during hospitalization shows that waking them early in the morning and awakening them by the doctors and nurses in mid of their sleep affects their sleep. Excessive light on the room also affects their sleep.

Figure 3: Bar graphs represent the association between gender and factor affecting the quality of sleep in hospitalised patients . $\mathrm{X}$ axis represents gender and $\mathrm{Y}$ axis represents the number of responses. Females have been affected more commonly than males by environmental, physiological and psychological factors. Chi square test was used to find the association between the variables, Pearson chi square value is 1.389 , p value is $0.499(>0.05)$ and was found to be statistically not significant.

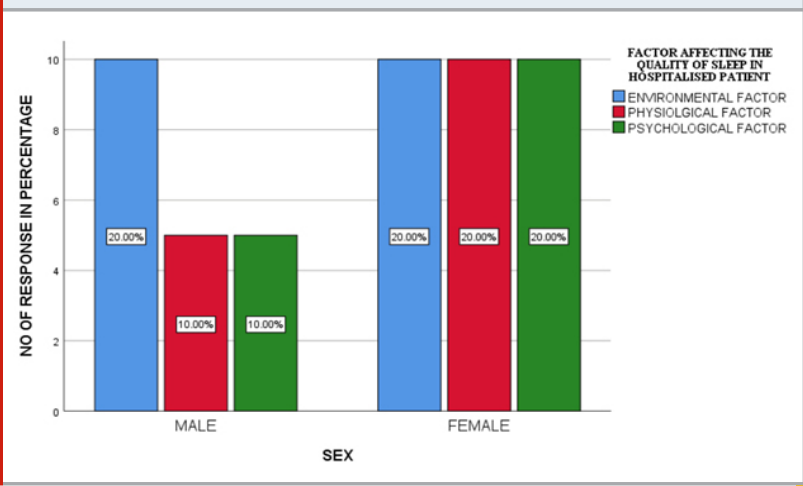


Figure 4 shows, Physiological factors like pain are experienced by $50 \%$ of pain, fatigue by $24 \%$ and discomfort by $26 \%$. It is similar to the study conducted in ICU ward, where pain, breathing difficulty and choking contributes to the sleep disturbances(Rahimi et al., 2018)).Figure 5 Bar graphs represent the association between gender and physiological factors affecting sleep. Females(36\%) have been affected more commonly than males (14\%)by pain.However the difference is not significant statistically. Pearson chi square value is 3.386, $\mathrm{p}$ value is $0.184(>0.05)$. Figure 6 shows environmental factors like uncomfortable bed position affects the sleep in $36 \%$ of the patient, restriction of tubes leads to cardiac monitor affects $26 \%$ of patients, i.v.(Intravenous injection) sets affect 38\% of the patient's sleep.

Figure 4: Pie chart shows the results on physiological factors affecting the quality of sleep in hospitalized patient $50 \%$ by pain(blue),24\% discomfortable(Green) and $26 \%$ fatigue(red)

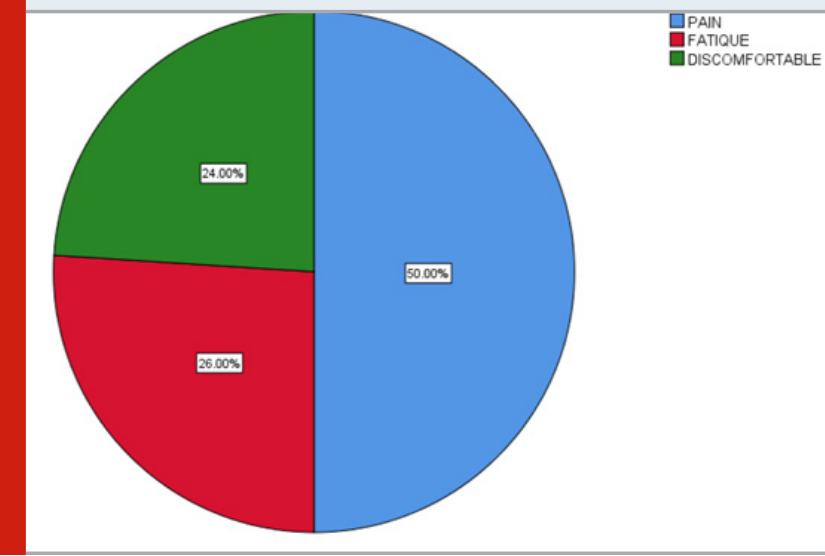

Figure 5 Bar graphs represent the association between gender and physiological factors affecting sleep. $\mathrm{X}$ axis represents gender and $\mathrm{Y}$ axis represents the number of responses.Females(36\%) have been affected more commonly than males $(14 \%)$ by pain. However the difference is not significant statistically. Pearson chi square value is $3.386, p$ value is $0.184(>0.05)$

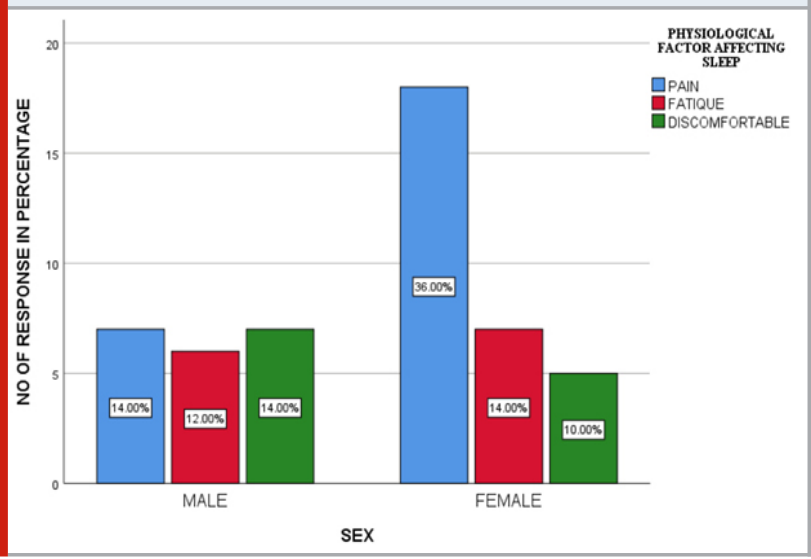

This is different from the study conducted in tertiary hospital, where noise of the monitor and telephone ringing are the major contributing factors of disturbed sleep (Institute of Medicine, Board on Health Sciences Policy and Committee on Sleep Medicine and Research, 2006).Figure 7 represents the association between gender and environment factors affecting sleep. From this graph we found that females are more affected than males by bed position and in i.v.set.However the difference is not statistically significant.Chi square test:Pearson chi square value is 0.057, $p$ value is $0.972(>0.05)$. Figure 8 shows that Psychological factors like lack of privacy affects $48 \%$, concern to medical expenses affects $22 \%$, due to fear of infectious diseases affects 30\% of the patients sleep.

Figure 6: Pie chart shows the results on environmental factors affecting the quality of sleep in hospitalized patients $36 \%$ of the study population responded to Bed position(blue),26 \% to cardiac monitoring sound(red) and $38 \%$ to i.v. set(green)

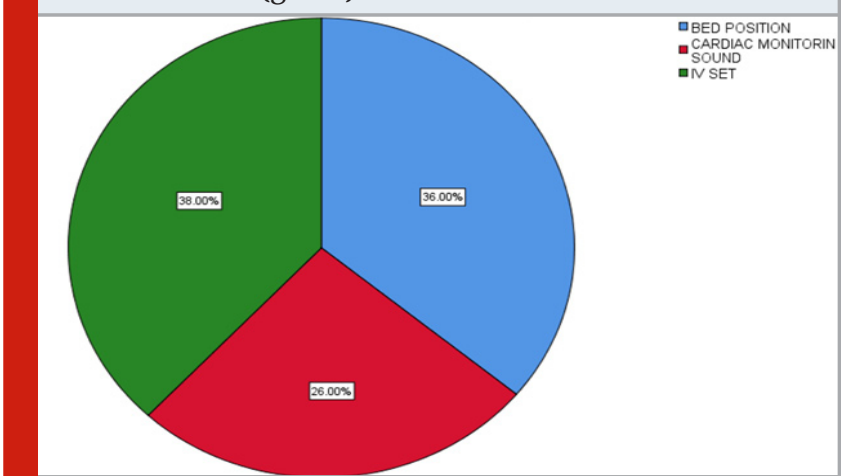

Figure 7: Bar graphs represent the association between gender and environment factors affecting sleep. $\mathrm{X}$ axis represents gender and $\mathrm{Y}$ axis represents the number of responses. From this graph we found that females are more affected than males by bed position and in i.v.set. However the difference is not statistically significant.Chi square test:Pearson chi square value is $0.057, \mathrm{p}$ value is $0.972(>0.05)$

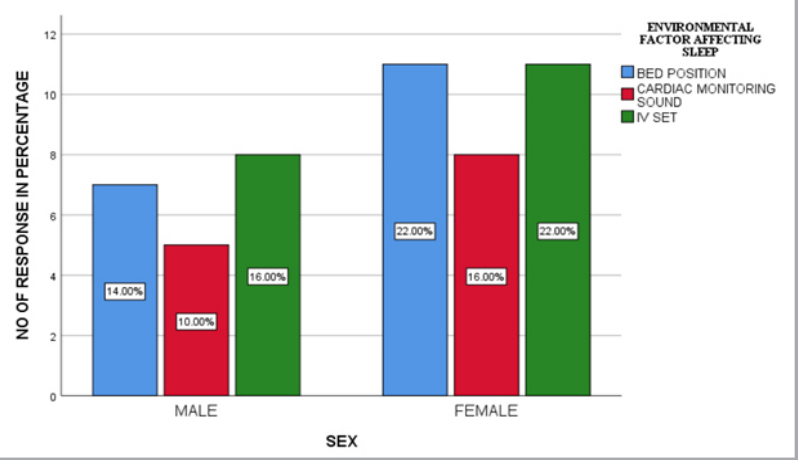

This finding is similar to the study which stated medical expenses and missing family members causes lack of sleep (da Costa and Ceolim, 2013).Figure 9 represents the 
association between gender and psychological factors. Females are more affected than males by bed position and in i.v. set. Chi square test was used to find the association between the variables, Pearson chi square value is $0.442, \mathrm{p}$ value is $0.802(>0.05)$ and was found to be statistically not significant. These facts suggest that sleep disturbances are more likely due to a combination of intrinsic and extrinsic factors that affect hospitalized patients, which can include the patient's personal illness and previous experiences in hospitalization (Reid, 2001)].

Figure 8: Pie chart shows the results on psychological factor factors affecting the quality of sleep in hospitalized patient $48 \%$ lack of privacy(blue), 22\% medical expensive (red) and 30\% fear of infectious diseases (green)

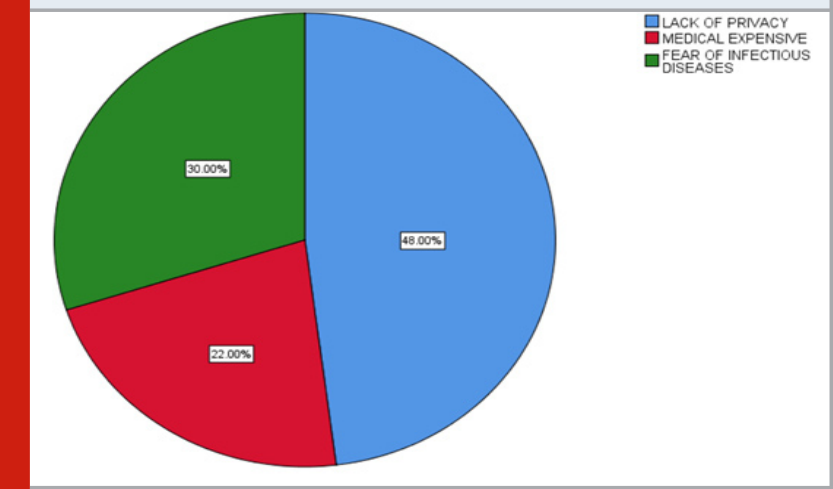

Figure 9: Bar graphs represent the association between gender and psychological factor .X axis represents gender and $\mathrm{Y}$ axis represents the number of responses. Females are more affected than males by bed position and in i.v. set. Chi square test was used to find the association between the variables, pearson chi square value is 0.442 , $\mathrm{p}$ value is $0.802(>0.05)$ and was found to be statistically not significant

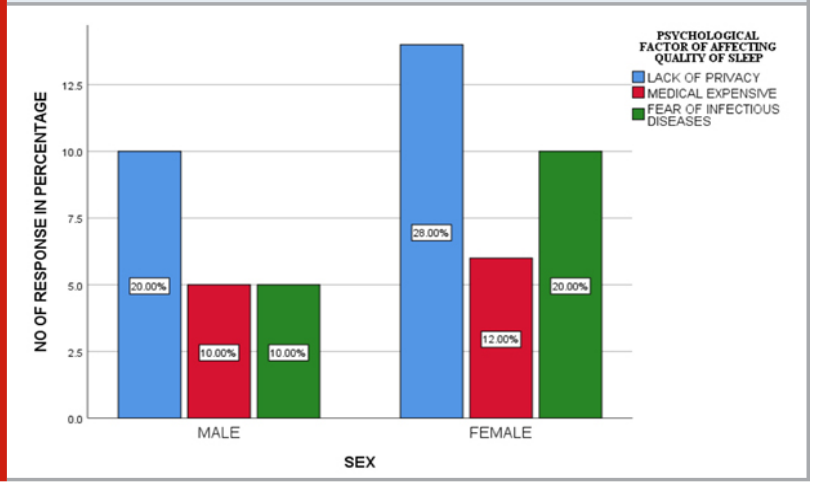

It is essential that nurses should understand the poor quality of sleep, which was reported by a large number of patients during hospitalization. The disturbed sleep pattern can have negative effects on patients' recovery. In a study undertaken in a coronary unit, lack of sleep was the second most frequent factor in increasing the recovery of patient from illness (Béphage, 2005)
(Tembo and Parker, 2009) (Marosti and Dantas, 2006; Young et al., 2008).Sleep is an important process of energy preservation, and its deprivation can cause sleepiness during the day, fatigue, altered mood and periods of disorientation(Marosti and Dantas, 2006; Young et al., 2008)(Çelik et al., 2005). It can also reduce pain tolerance due to the increase of fatigue in the sympathetic central nervous system, which may lead to increased use of pain control drugs, which can themselves contribute to sleep deprivation(Meyer et al., 1994). Sleep, therefore, constitutes a basic human need that deserves full attention and intervention by hospital health care takers (Redding, Hargest and Minsky, 1977) .As the sample of the study is small,the factors affecting the quality of sleep may differ from other articles. A clear picture of demographic data was not collected to know about their socioeconomic status.

\section{CONCLUSION}

It can be concluded that sleeping patterns of patients are affected by so many factors, especially by environmental and psychological factors. When compared to males, females were more affected by the factors affecting sleep when they are hospitalised. On analyzing all these factors, the quality of sleep can be improved by providing a comfortable environment and psychological counselling to the patients. Nurses should consult with doctors and plan accordingly to prevent sleep disturbances.

\section{ACKNOWLEDGEMENTS}

We thank Saveetha Dental College and the participants of this study for their support to conduct the survey.

\section{CONFLICT OF INTEREST: None to declare}

\section{REFERENCES}

Adam, K. and Oswald, I. (1977) 'Sleep is for tissue restoration', Journal of the Royal College of Physicians of London, 11(4), pp. 376-388.

Béphage, G. (2005) 'Promoting quality sleep in older people: the nursing care role', The British journal of nursing, 14(4), pp. 205-210.

Besedovsky, L., Lange, T. and Born, J. (2012) 'Sleep and immune function', Pflügers Archiv - European Journal of Physiology, pp. 121-137. doi: 10.1007/s00424-0111044-0.

Çelik, S. et al. (2005) 'Sleep disturbance: the patient care activities applied at the night shift in the intensive care unit', Journal of Clinical Nursing, pp. 102-106. doi: 10.1111/j.1365-2702.2004.01010.x.

da Costa, S. V. and Ceolim, M. F. (2013) '[Factors that affect inpatients' quality of sleep]', Revista da Escola de Enfermagem da U S P, 47(1), pp. 46-52.

Dogan, O., Ertekin. and Dogan, S. (2005) 'Sleep quality 
in hospitalized patients', Journal of Clinical Nursing, pp. 107-113. doi: 10.1111/j.1365-2702.2004.01011.x.

Fabbri, M. et al. (2006) 'Postural control after a night without sleep', Neuropsychologia, pp. 2520-2525. doi: 10.1016/j.neuropsychologia.2006.03.033.

Gangwisch, J. E. et al. (2006) 'Short sleep duration as a risk factor for hypertension: analyses of the first National Health and Nutrition Examination Survey', Hypertension, 47(5), pp. 833-839.

Institute of Medicine, Board on Health Sciences Policy and Committee on Sleep Medicine and Research (2006) Sleep Disorders and Sleep Deprivation: An Unmet Public Health Problem. National Academies Press.

Júnior, M. G. da S. et al. (2014) 'Tannure MC, Gonçalves AMP. Nursing Care Systematization: A practical guide. 2nd ed. Rio de Janeiro, RJ: Guanabara Koogan; 2010', Revista da Rede de Enfermagem do Nordeste. doi: 10.15253/2175-6783.2014000300021.

Knutson, K. L. et al. (2007) 'The metabolic consequences of sleep deprivation', Sleep Medicine Reviews, pp. 163-178. doi: 10.1016/j.smrv.2007.01.002.

Marosti, C. A. and Dantas, R. A. S. (2006) 'Avaliação dos pacientes sobre os estressores em uma unidade coronariana', Acta Paulista de Enfermagem, pp. 190195. doi: 10.1590/s0103-21002006000200010.

Meyer, T. J. et al. (1994) 'Adverse Environmental Conditions in the Respiratory and Medical ICU Settings', Chest, pp. 1211-1216. doi: 10.1378/chest.105.4.1211.

'NIH State-of-the-Science Conference Statement on Manifestations and Management of Chronic Insomnia in Adults' (2009) FOCUS, pp. 538-546. doi: 10.1176/ foc.7.4.foc538.

Ogawa, Y. et al. (2003) 'Total Sleep Deprivation Elevates Blood Pressure Through Arterial Baroreflex Resetting: a Study with Microneurographic Technique', Sleep, pp. 986-989. doi: 10.1093/sleep/26.8.986.

Rahimi, M. et al. (2018) 'The Relationship of Discomforting Factors with Coping Strategies Among Patients in
Cardiac Surgery Intensive Care Units', Critical Care Nursing. doi: 10.5812/ccn.63763.

Redding, J. S., Hargest, T. S. and Minsky, S. H. (1977) 'How noisy is intensive care?', Critical care medicine, 5(6), pp. 275-276.

Reid, E. (2001) 'Factors affecting how patients sleep in the hospital environment', The British journal of nursing, 10(14), pp. 912-915.

Rosenberg, C. (1990) 'Sleep and Alertness: Chronobiological, Behavioral, and Medical Aspects of Napping', Neurology, pp. 869-869. doi: 10.1212/ wnl.40.5.869-c.

Shenoy, P. B. and Brundha, M. P. (2016) 'Awareness of polycystic ovarian disease among females of age group 18-30 years', Research journal of pharmaceutical, biological and chemical sciences. Journal of Pharmaceutical Sciences and Research, 8(8), p. 813.

Sin, C. W. M., Ho, J. S. C. and Chung, J. W. Y. (2009) 'Systematic review on the effectiveness of caffeine abstinence on the quality of sleep', Journal of clinical nursing, 18(1), pp. 13-21.

Tembo, A. C. and Parker, V. (2009) 'Factors that impact on sleep in intensive care patients', Intensive \&t critical care nursing: the official journal of the British Association of Critical Care Nurses, 25(6), pp. 314-322.

Tranmer, J. E. et al. (2003) 'The sleep experience of medical and surgical patients', Clinical nursing research, 12(2), pp. 159-173.

Whitehead, A. (1976) 'Introduction to Psychology. Sixth edition. By Ernest R. Hilgard, Richard C. Atkinson and Rita L. Atkinson New York: Harcourt Brace Jovanovich. 1975. Pp xiii 658. Index 14 pp. Illustrated. No price stated', British Journal of Psychiatry, pp. 300-300. doi: 10.1192/s0007125000092515.

Young, J. S. et al. (2008) 'Sleep in hospitalized medical patients, Part 1: Factors affecting sleep', Journal of Hospital Medicine, pp. 473-482. doi: 10.1002/ jhm.372. 